\title{
Aplicação complementar de enxofre em diferentes doses na cultura do alho
}

\author{
Juliano Tadeu V de Resende ${ }^{1}$; Rafael Gustavo F Morales ${ }^{1}$; Francisco V Resende ${ }^{2}$; Rafaela Carminatti ${ }^{1}$; \\ Leandro Luiz da C Bertuzzo ${ }^{1}$; Alex Sandro T Figueiredo ${ }^{1}$ \\ 'UNICENTRO, C. Postal 3010, 85040-080 Guarapuava-PR; jresende@unicentro.br; ${ }^{2}$ Embrapa Hortaliças, C. Postal 218, 70359-970 \\ Brasília-DF; fresende@enph.embrapa.br
}

\begin{abstract}
RESUMO
O desenvolvimento do alho e possíveis variações entre cultivares em resposta à adubação com enxofre (S), não somente em termos de aumento de produtividade, mas também quanto às características de desenvolvimento do bulbo e da planta, ainda é pouco conhecido. Desta forma, o objetivo deste trabalho foi avaliar o efeito da adubação complementar com enxofre elementar $\left(\mathrm{S}^{\circ}\right)$ sobre a produtividade de bulbos em três cultivares de alho, bem como seu efeito em diversas características ligadas à morfologia e crescimento do bulbo e da planta. Os tratamentos foram dispostos em esquema fatorial $3 \times 3$, compreendendo três cultivares (Roxo Pérola de Caçador, Quitéria e Roxo Caxiense) e três doses de $\mathrm{S}^{\circ}\left(0,50\right.$ e $\left.100 \mathrm{~kg} \mathrm{ha}^{-1}\right)$. O delineamento experimental foi em blocos casualizados com três repetições. Foram avaliados a produtividade; número médio de folhas; altura média de plantas; massa fresca e seca de folhas, pseudocaule, bulbo e sistema radicular; comprimento de raízes; e teores de $\mathrm{S}$ e fósforo (P) nas folhas e no bulbo. A adubação com $\mathrm{S}^{\circ}$ induziu aumento da produtividade das três cultivares, com destaque para a cultivar Roxo Pérola de Caçador, que apresentou o maior incremento. $\mathrm{O}$ aumento da produtividade esteve fortemente relacionado ao aumento do vigor da planta, como altura, número de folhas e massa fresca e seca de folhas, pseudocaule e raízes.
\end{abstract}

Palavras-chave: Allium sativum, nutrição mineral, resposta fisiológica.

\begin{abstract}
Complementary application of sulfur at different doses on garlic plants

The garlic behavior and possible variations among cultivars in response to fertilization with sulfur (S), not only in terms of productivity, but also on the characteristics of the bulb and plant development is still unknown. Thus, the aim of this study was to evaluate the effects of additional fertilization with elemental sulfur $\left(\mathrm{S}^{\circ}\right)$ on the bulb yield of three cultivars of garlic, and its effect on several traits of morphology and growth of the bulb and plant. The treatments were arranged in a factorial $3 \times 3$, comprising three cultivars (Roxo Pérola de Caçador, Quitéria and Roxo Caxiense) and three doses of $\mathrm{S}^{\circ}\left(0,50\right.$ and $\left.100 \mathrm{~kg} \mathrm{ha}^{-1}\right)$. The experimental design was randomized blocks with three replications. We evaluated the yield; number of leaves; plant height; fresh and dry mass of leaves, pseudostem, bulb and root system; root length; and levels of S and phosphorus $(\mathrm{P})$ on leaves and bulbs. The fertilization with $\mathrm{S}^{\circ}$ induced increased yield of the three cultivars, especially the cultivar Roxo Pérola Caçador that presented the greatest increase. The increased yield was strongly related to plant vigor, such as height, leaf number and fresh and dry mass of leaves, pseudostem and roots.
\end{abstract}

Keywords: Allium sativum, mineral nutrition, physiological response.

\section{(Recebido para publicação em 17 de dezembro de 2009; aceito em 4 de abril de 2011)}

\section{(Received on December 17, 2009; accepted on April 4, 2011)}

\begin{abstract}
A produção brasileira de alho é insuficiente para atender à demanda do mercado interno, bem como às exigências de qualidade do consumidor. A baixa competitividade do alho nacional com o argentino e chinês é o principal fator limitante à expansão da cultura no Brasil, por apresentarem menores custos de produção, clima mais favorável e políticas de subsídios (Souza \& Macedo, 2009). Os manejos inadequados da irrigação e da adubação também devem ser levados em consideração, por serem decisivos para produção de alho de boa qualidade (Oliveira et al., 2004). Quanto à adubação, os estudos têm se concentrado em sua maioria com nitrogênio, potássio, fósforo, magnésio,
\end{abstract}

boro e zinco, desconsiderando os demais nutrientes.

Pouca ênfase é dada à adubação com enxofre (S), pois a maioria dos fertilizantes utilizados na agricultura apresentava consideráveis teores desse elemento que, em parte, supririam a demanda das culturas. No entanto, o surgimento de novos fertilizantes formulados com baixo teor ou ausência de $\mathrm{S}$, altas produtividades com exportação do elemento, redução da concentração ou mesmo inexistência de $\mathrm{S}$ na formulação dos agrotóxicos atuais, uso de queimadas e a diminuição do teor de matéria orgânica do solo contribuem, grandemente, para a baixa disponibilidade desse nutriente às plantas (Furtini Neto et al., 2000; Scherer, 2001; Smatanová et al., 2004). Desta forma, começaram a surgir problemas nutricionais em culturas que demandam quantidades elevadas do nutriente, como é o caso das Alliaceae, sendo o S o terceiro nutriente em importância para essa família (Alvarez \& Dias, 1996).

As principais fontes de $\mathrm{S}$ na agricultura são a adubação orgânica, alguns adubos químicos, como o sulfato de amônio e de potássio, e o $\mathrm{S}$ na sua forma elementar $\left(\mathrm{S}^{\circ}\right)$. Este último, dependendo da característica do solo, pode interferir na dinâmica de outros nutrientes. A adição de $S^{\circ}$ ao solo estimula a solubilização do fósforo (P), o qual é oxidado por microrganismos do gênero Thiobacillus 
(Scherer, 2001). Entretanto, a adubação com $\mathrm{S}^{\circ}$ forma ácido sulfúrico, que pode disponibilizar nutrientes antes insolúveis, como o $\mathrm{P}$, mas que em altas concentrações inibe a atividade dos microrganismos que transformam $\mathrm{S}^{\circ}$ em S-sulfato (Haneklaus et al., 1997).

A adubação com $\mathrm{S}$ proporcionou aumento na produção de diversas culturas. A aplicação de S em cobertura na cultura do feijoeiro induziu aumento da produção de massa seca da parte aérea, do número de vagens por planta e da produtividade de grãos (Crusciol et al., 2006). Na cultura da canola, a adubação sulfurada (20 $\mathrm{kg} \mathrm{ha}^{-1}$ de $\mathrm{S}$ ) induziu aumento dos teores de óleo, tioglicosídeos e proteínas (Ahmad et al., 2007). Contudo, pouco se sabe sobre o desenvolvimento do alho em resposta à adubação com $\mathrm{S}$, não apenas em produtividade, mas quanto às características do bulbo e da planta. Desta forma, o objetivo deste trabalho foi avaliar o efeito da adubação complementar com $\mathrm{S}^{\text {o }}$ sobre a produtividade de diferentes cultivares de alho, bem como seu efeito em diversas características da fisiologia do bulbo e da planta.

\section{MATERIAL E MÉTODOS}

O experimento foi conduzido no Setor de Olericultura, da Universidade Estadual do Centro-Oeste (Unicentro), em Guarapuava-PR (2523'36"S; $51^{\circ} 27^{\prime} 19^{\prime \prime} \mathrm{W}$, altitude $1120 \mathrm{~m}$ ), entre os meses de junho e novembro de 2007. O clima da área é classificado como Cfb (subtropical mesotérmico úmido), sem estação seca, com verões frescos e invernos moderados, conforme a classificação de Koppen (1931). A precipitação média anual é 1944 mm, temperatura média mínima anual de $12,7^{\circ} \mathrm{C}$, temperatura média máxima anual de $23,5^{\circ} \mathrm{C}$ e umidade relativa do ar de 77,9\% (Thomaz \& Vestena, 2003).

O solo é classificado como Latossolo Bruno Distroférrico típico de textura argilosa (Embrapa, 2006). A análise de solo na área experimental apresentou a seguinte composição química: $\mathrm{pH}$ $\left(\mathrm{CaCl}_{2}\right)=5,7 ; \mathrm{H}^{+}+\mathrm{Al}^{+++}=3,46 \mathrm{cmol}$ $\mathrm{dm}^{-3} ; \mathrm{Ca}^{++}=6,0 \mathrm{cmol}_{\mathrm{c}} \mathrm{dm}^{-3} ; \mathrm{Mg}^{++}=4,3$ $\mathrm{cmol}_{\mathrm{c}} \mathrm{dm}^{-3} ; \mathrm{P}$ (resina) $=10,1 \mathrm{mg} \mathrm{dm}^{-3}$; $\mathrm{K}^{+}=0,43 \mathrm{cmol}_{\mathrm{c}} \mathrm{dm}^{-3} ; \mathrm{S}=5,1 \mathrm{mg} \mathrm{dm}^{-3}$; matéria orgânica $=51,00 \mathrm{~g} \mathrm{dm}^{-3}$; $\mathrm{CTC}=$ $14,19 \mathrm{cmol}_{\mathrm{c}} \mathrm{dm}^{-3}$ e V\%=75,6\%.

$\mathrm{O}$ delineamento experimental foi em blocos casualizados com três repetições e os tratamentos dispostos em esquema fatorial 3x3, compreendendo três cultivares de alho (Roxo Pérola de Caçador, Quitéria e Roxo Caxiense) e três doses de $S^{\circ}\left(0,50\right.$ e $\left.100 \mathrm{~kg} \mathrm{ha}^{-1}\right)$. O plantio foi realizado em parcelas de $2 \mathrm{~m}$ de comprimento e $1 \mathrm{~m}$ de largura. Os bulbilhos foram plantados com IVD (índice de superação de dormência) superior a 70\% com ápice para cima na profundidade de $5 \mathrm{~cm}$. O espaçamento foi de $10 \mathrm{~cm}$ entre plantas e $20 \mathrm{~cm}$ entre linhas, totalizando 100 plantas por unidade experimental. Como bordadura desconsideraram-se 25 $\mathrm{cm}$ de ambas as extremidades de cada parcela, permanecendo-se com área útil de $1,5 \mathrm{~m}^{2}$ (80 plantas).

A adubação de plantio foi realizada com base na análise do solo, seguindo-se as recomendações de Raij et al. (1996), utilizando-se, por parcela, 6 g de uréia, $50 \mathrm{~g}$ de monofosfato de amônio e $28 \mathrm{~g}$ de cloreto de potássio. A adubação com $\mathrm{S}^{\circ}$ (produto comercial com $95 \%$ de $\mathrm{S}$ ) foi em cobertura, parcelada aos 50, 80 e 100 dias após o plantio, utilizando-se $300 \mathrm{~g}$ de material inerte (areia lavada) para melhor homogeneização no momento da aplicação. Juntamente com a aplicação dos tratamentos foi realizada a adubação de cobertura com $12 \mathrm{~g}$ de uréia e $16 \mathrm{~g}$ de cloreto de potássio. A adubação foliar foi realizada com $2 \mathrm{~kg} \mathrm{ha}^{-1}$ de ácido bórico, 70 e 90 dias após o plantio, e $1 \mathrm{~kg} \mathrm{ha}^{-1} \mathrm{de}$ óxido de zinco, 80 dias após o plantio. A cultura foi submetida à irrigação por aspersão, quando necessário.

O controle fitossanitário foi realizado com duas pulverizações de Mancozeb (2,0 kg ha-1), visando prevenir o aparecimento de ferrugem (Puccinia allii) e alternária (Alternaria porri). Para o controle de ácaros e tripes foi aplicado Thiometon a cada 30 dias. A cultura foi mantida livre de plantas daninhas por meio de capinas manuais.

Avaliou-se em 10 plantas de cada parcela aos 100 dias após o plantio: número de folhas, desconsiderando-se as folhas em avançado estado de senescência; altura das plantas desde o ápice foliar até o solo; massa fresca das folhas, pseudocaule e sistema radicular; massa seca das folhas, pseudocaule e sistema radicular, secando-se o material em estufa a $105^{\circ} \mathrm{C}$, durante 48 horas; e, a partir da massa seca, foram determinados os teores de $\mathrm{S}$ e $\mathrm{P}$ em amostras de folhas e de bulbos de seis plantas por parcela.

Aos 178 dias após o plantio, quando as plantas apresentavam sinais avançados de maturação, caracterizados pelo amarelecimento e secamento parcial da parte aérea, realizou-se a colheita, não se observando diferença no ciclo das cultivares. Após a colheita, determinou-se o comprimento de raízes, medindo-se desde a região do "prato" até a extremidade das raízes mais longas. Em seguida, os bulbos foram submetidos ao processo de cura, durante 50 dias, para então serem realizadas as seguintes avaliações: produtividade, massa média e massa seca de bulbos.

Os dados obtidos foram submetidos à análise de variância e as médias das cultivares e das doses foram comparadas pelo teste Tukey a 5\% de probabilidade. Visando estabelecer possíveis correlações entre o desenvolvimento vegetativo e a produção de bulbos sob influência da adubação sulfurada, foram determinados os coeficientes r, testados pelo teste $\mathrm{t}(5 \%)$.

\section{RESULTADOS E DISCUSSÃO}

A adubação complementar com $\mathrm{S}^{\circ}$ induziu aumento da produtividade média das três cultivares, em $22 \%$. Comparando as cultivares dentro de cada dose, evidenciou-se que a cultivar Roxo Pérola de Caçador teve a menor produtividade na ausência da adubação sulfurada. Esse fato pode estar relacionado à sua menor capacidade fotossintética em solos com baixo teor de $\mathrm{S}$, reduzindo a síntese de proteínas e, por conseguinte, a produtividade (Marschner, 1995). No entanto, com o aumento das doses de $\mathrm{S}^{\circ}$, a produtividade dessa cultivar também aumentou, apresentando o maior incremento entre as cultivares $(32,30 \%)$, não existindo mais diferença entre elas na dose máxima (Tabela 1). $\mathrm{O}$ aumento da produtividade está relacionado diretamente com o aumento da massa média de bulbos, obtendo-se correlação de $0,97 * *$ entre esses fatores. Apesar do aumento da massa média de 
Tabela 1. Produtividade; massa fresca média e massa seca de bulbos; altura da planta; massa fresca e massa seca de folhas, do pseudocaule e de raízes; teor de enxofre e de fósforo das folhas e do bulbo; número médio de folhas e comprimento de raízes das cultivares de alho Roxo Pérola de Caçador, Quitéria e Roxo Caxiense em função da adubação complementar com enxofre elementar (yield, average weight and dry weight of bulbs, plant height, fresh and dry weight of leaves, pseudostem and roots, sulfur and phosphorus from the leaves and bulb, number of leaves and roots of the garlic cultivars Roxo Pérola de Caçador, Quitéria and Roxo Caxiense as a result of fertilization with additional elemental sulfur). Guarapuava, UNICENTRO, 2007.

\begin{tabular}{|c|c|c|c|c|c|c|}
\hline \multirow{3}{*}{ Cultivar } & \multicolumn{6}{|c|}{ Doses de enxofre $\left(\mathrm{kg} \mathrm{ha}^{-1}\right)$} \\
\hline & $\mathbf{0}$ & 50 & 100 & $\mathbf{0}$ & 50 & 100 \\
\hline & \multicolumn{3}{|c|}{ Produtividade (t ha-1) } & \multicolumn{3}{|c|}{ Massa média de bulbos (g) } \\
\hline$\overline{\text { Roxo Pérola de Caçador }}$ & $8,42 \mathrm{bB}$ & $8,62 \mathrm{bB}$ & $11,14 \mathrm{aA}$ & $32,00 \mathrm{bC}$ & $35,00 \mathrm{bB}$ & $43,00 \mathrm{aA}$ \\
\hline Quitéria & $9,61 \mathrm{aC}$ & $10,55 \mathrm{aB}$ & $11,70 \mathrm{aA}$ & $30,00 \mathrm{cC}$ & $38,00 \mathrm{aB}$ & $41,00 \mathrm{bA}$ \\
\hline \multirow[t]{2}{*}{ Roxo Caxiense } & $10,18 \mathrm{aB}$ & $10,75 \mathrm{aB}$ & $11,66 \mathrm{aA}$ & $34,00 \mathrm{aC}$ & $37,00 \mathrm{aB}$ & $40,00 \mathrm{bA}$ \\
\hline & \multicolumn{3}{|c|}{ Massa seca de bulbos (g) } & \multicolumn{3}{|c|}{ Altura média de plantas (cm) } \\
\hline Roxo Pérola de Caçador & $6,12 \mathrm{aA}$ & 5,65 aA & $7,40 \mathrm{aA}$ & $73,71 \mathrm{bB}$ & $75,75 \mathrm{bB}$ & $80,76 \mathrm{bA}$ \\
\hline Quitéria & $3,52 \mathrm{bA}$ & $3,67 \mathrm{bA}$ & $3,33 \mathrm{bA}$ & $80,33 \mathrm{aB}$ & $81,75 \mathrm{aB}$ & $87,01 \mathrm{aA}$ \\
\hline \multirow[t]{2}{*}{ Roxo Caxiense } & $4,15 \mathrm{bA}$ & $2,98 \mathrm{bA}$ & $3,88 \mathrm{bA}$ & $70,01 \mathrm{bC}$ & $74,05 \mathrm{bB}$ & $79,79 \mathrm{bA}$ \\
\hline & \multicolumn{3}{|c|}{ Massa fresca de folhas (g) } & \multicolumn{3}{|c|}{ Massa seca de folhas (g) } \\
\hline Roxo Pérola de Caçador & $21,42 \mathrm{bB}$ & $21,56 \mathrm{bB}$ & $24,81 \mathrm{cA}$ & $6,05 \mathrm{bB}$ & $5,80 \mathrm{bC}$ & $6,80 \mathrm{bA}$ \\
\hline Quitéria & $27,43 \mathrm{aA}$ & $28,69 \mathrm{aA}$ & $27,56 \mathrm{bA}$ & $7,42 \mathrm{aA}$ & $7,61 \mathrm{aA}$ & $7,64 \mathrm{bA}$ \\
\hline \multirow[t]{2}{*}{ Roxo Caxiense } & $28,56 \mathrm{aB}$ & $32,25 \mathrm{aB}$ & $37,35 \mathrm{aA}$ & $7,52 \mathrm{aC}$ & $8,26 \mathrm{aB}$ & $9,37 \mathrm{aA}$ \\
\hline & \multicolumn{3}{|c|}{ Massa fresca de pseudocaule (g) } & \multicolumn{3}{|c|}{ Massa seca de pseudocaule (g) } \\
\hline Roxo Pérola de Caçador & $15,53 \mathrm{bC}$ & $21,99 \mathrm{bB}$ & $30,00 \mathrm{aA}$ & $5,84 \mathrm{bB}$ & $4,85 \mathrm{bC}$ & $7,94 \mathrm{abA}$ \\
\hline Quitéria & $26,26 \mathrm{aB}$ & $32,10 \mathrm{aA}$ & $28,78 \mathrm{aAB}$ & $6,13 \mathrm{aB}$ & $7,43 \mathrm{aA}$ & $7,70 \mathrm{bA}$ \\
\hline \multirow[t]{2}{*}{ Roxo Caxiense } & $22,83 \mathrm{aC}$ & $28,06 \mathrm{aB}$ & $33,71 \mathrm{aA}$ & $5,80 \mathrm{bC}$ & $6,47 \mathrm{aB}$ & $8,43 \mathrm{aA}$ \\
\hline & \multicolumn{3}{|c|}{ Teor de enxofre foliar (\%) } & \multicolumn{3}{|c|}{ Teor de enxofre no bulbo (\%) } \\
\hline$\overline{\text { Roxo Pérola de Caçador }}$ & $0,61 \mathrm{bB}$ & $0,63 \mathrm{cAB}$ & $0,66 \mathrm{bA}$ & $0,84 \mathrm{aB}$ & $0,92 \mathrm{aA}$ & $0,91 \mathrm{aA}$ \\
\hline Quitéria & $0,90 \mathrm{aB}$ & $0,90 \mathrm{aB}$ & $1,00 \mathrm{aA}$ & $0,69 \mathrm{bC}$ & $0,76 \mathrm{bB}$ & $0,86 \mathrm{aA}$ \\
\hline \multirow[t]{2}{*}{ Roxo Caxiense } & $0,69 \mathrm{bB}$ & $0,81 \mathrm{bA}$ & $0,73 \mathrm{bB}$ & $0,51 \mathrm{bB}$ & $0,58 \mathrm{cA}$ & $0,60 \mathrm{bA}$ \\
\hline & \multicolumn{3}{|c|}{ Número médio de folhas por planta } & \multicolumn{3}{|c|}{ Massa fresca de raízes (g) } \\
\hline$\overline{\text { Roxo Pérola de Caçador }}$ & $6,43 \mathrm{aB}$ & $6,46 \mathrm{aB}$ & $6,89 \mathrm{aA}$ & $4,73 \mathrm{aC}$ & $5,32 \mathrm{aB}$ & $6,02 \mathrm{aA}$ \\
\hline Quitéria & $6,20 \mathrm{aA}$ & $6,13 \mathrm{aA}$ & $6,50 \mathrm{aA}$ & $5,50 \mathrm{aC}$ & $7,51 \mathrm{aB}$ & $8,72 \mathrm{aA}$ \\
\hline \multirow[t]{2}{*}{ Roxo Caxiense } & $7,16 \mathrm{aB}$ & $7,03 \mathrm{aB}$ & $8,03 \mathrm{aA}$ & $5,75 \mathrm{aC}$ & $6,88 \mathrm{aB}$ & $7,53 \mathrm{aA}$ \\
\hline & \multicolumn{3}{|c|}{ Comprimento da raiz (cm) } & \multicolumn{3}{|c|}{ Massa seca de raízes (g) } \\
\hline Roxo Pérola de Caçador & $15,63 \mathrm{bC}$ & $17,83 \mathrm{aB}$ & $20,17 \mathrm{aA}$ & $1,20 \mathrm{bA}$ & $1,13 \mathrm{bA}$ & $1,45 \mathrm{aA}$ \\
\hline Quitéria & $18,90 \mathrm{aA}$ & $17,50 \mathrm{aA}$ & $17,92 \mathrm{bA}$ & $1,53 \mathrm{aA}$ & $1,38 \mathrm{aA}$ & $1,66 \mathrm{aA}$ \\
\hline \multirow[t]{2}{*}{ Roxo Caxiense } & $17,52 \mathrm{abA}$ & $17,03 \mathrm{aA}$ & $18,17 \mathrm{abA}$ & $1,60 \mathrm{aA}$ & $1,47 \mathrm{aA}$ & $1,64 \mathrm{aA}$ \\
\hline & \multicolumn{3}{|c|}{ Teor de fósforo foliar (\%) } & \multicolumn{3}{|c|}{ Teor de fósforo no bulbo (\%) } \\
\hline Roxo Pérola de Caçador & $0,37 \mathrm{bB}$ & $0,39 \mathrm{abAB}$ & $0,42 \mathrm{aA}$ & $0,47 \mathrm{aA}$ & $0,43 \mathrm{bAB}$ & $0,40 \mathrm{bB}$ \\
\hline Quitéria & $0,42 \mathrm{aA}$ & $0,37 \mathrm{bB}$ & $0,37 \mathrm{bB}$ & $0,47 \mathrm{aA}$ & $0,48 \mathrm{aA}$ & $0,48 \mathrm{aA}$ \\
\hline Roxo Caxiense & $0,42 \mathrm{aA}$ & $0,41 \mathrm{aA}$ & $0,39 \mathrm{abA}$ & $0,38 \mathrm{bB}$ & $0,47 \mathrm{aA}$ & $0,50 \mathrm{aA}$ \\
\hline
\end{tabular}

Médias seguidas pela mesma letra minúscula na coluna e maiúscula na linha não diferem significativamente entre si, pelo teste de Tukey $(p=0,05)$ (means followed by the same small letter in the columns and same capital letter in the line did not differ from each other by the Tukey test $(\mathrm{p}=0,05))$.

bulbos não se traduzir em incremento de massa seca do mesmo, Lancaster \& Randle (2002) demonstraram que o fornecimento adequado de $\mathrm{S}$ influenciou a produção de bulbos, incrementando a massa seca e alterando a intensidade do sabor (pungência) dos bulbos de plantas do gênero Allium.
$\mathrm{O}$ aumento da produtividade apresentou elevada correlação com o aumento do vigor da planta, como o aumento da altura $(\mathrm{r}=0,99 * *)$; massa fresca $\left(\mathrm{r}=0,99^{* *}\right)$, massa seca $\left(\mathrm{r}=0,99^{* *}\right) \mathrm{e}$ número médio de folhas $(\mathrm{r}=0,94 * *)$; comprimento $\left(\mathrm{r}=0,98^{* *}\right)$, massa fresca $\left(\mathrm{r}=0,93^{* *}\right)$ e massa seca de raízes $(\mathrm{r}=$
$0,74 *)$; e massa fresca $(\mathrm{r}=0,92 * *)$ e massa seca do pseudocaule $(\mathrm{r}=0,99 * *)$.

A altura média de plantas aumentou em todas as cultivares em função das doses de $\mathrm{S}^{\circ}$ (Tabela 1). A cultivar Roxo Caxiense apresentou o maior incremento na altura $(13,97 \%)$ e a cultivar Quitéria a maior altura média, independente 
da dose de $\mathrm{S}^{\circ}$. Essa superioridade pode estar relacionada a algum fator externo, não avaliado neste trabalho, ou à própria característica da cultivar. Apesar de a altura ter apresentado correlação positiva com rendimento, Figliuolo et al. (2001) não observaram relação significativa entre os mesmos. O incremento na altura pode estar relacionado à nutrição mineral, havendo relatos de que o nitrogênio, o potássio e o fósforo podem influenciar na altura de plantas (Souza \& Casali, 1986); entretanto, não foram encontrados relatos em relação ao $\mathrm{S}$.

A massa fresca de folhas aumentou em duas das três cultivares, sendo maior na cultivar Roxo Caxiense (28,56 para $37,35 \mathrm{~g})$. Avaliando-se as cultivares dentro de cada dose, a cultivar Roxo Pérola de Caçador apresentou a menor massa fresca de folhas nas três doses e a Roxo Caxiense a maior, entretanto, diferindo-se da cultivar Quitéria apenas na dose máxima (Tabela 1). A superioridade da cultivar Roxo Caxiense para essa característica refletiu em aumento da sua massa seca de folhas e a cultivar Roxo Pérola de Caçador apresentou aumento inconsistente entre as doses.

As massas fresca e seca do pseudocaule aumentaram com as doses de $\mathrm{S}^{\circ}$, apresentando uma correlação positiva e significativa entre si $\left(r=0,86^{*}\right)$. A cultivar Roxo Pérola de Caçador apresentou a menor massa fresca sob as doses de $0 \mathrm{e}$ 50 t ha $^{-1}$ de $\mathrm{S}^{\mathrm{o}}$; entretanto, o incremento em praticamente $100 \%$ obtido sob a dose máxima fez com que a mesma se igualasse estatisticamente às demais (Tabela 1). A cultivar Roxo Caxiense também apresentou incremento elevado de massa fresca $(45,34 \%)$ e, igualmente ao observado com a cultivar Roxo Pérola de Caçador, esse incremente se traduziu em aumento da massa seca do pseudocaule. $\mathrm{O}$ aumento das massas fresca e seca de folhas e do pseudocaule pode estar relacionado ao incremento do S na planta e se deve, presumivelmente, ao fato de o S ser componente fundamental para a formação de aminoácidos como cisteína e metionina, vitaminas, enzimas e coenzimas (Haneklaus et al., 1997). Esses aminoácidos são componentes fundamentais na formação de proteínas, desempenhando papel estrutural, além de participarem de diversas rotas metabólicas na planta (Smatanová et al., 2004; Caballero et al., 2001). Se o suprimento desse nutriente for adequado, ocorre o desenvolvimento mais acelerado da planta, com aumento do índice de área foliar e, consequentemente, a sua capacidade fotossintética (Stahlschmidt et al., 1997). Esse fato reflete no aumento do vigor da planta, mensurável por meio do incremento de massa fresca e seca de diversos tecidos vegetais, tendo como consequência, o aumento da produtividade.

Houve tendência de aumento no número de folhas sob a maior dose de $\mathrm{S}^{\circ}$, fato esse relacionado ao efeito indireto do nutriente na menor senescência das folhas devido ao aumento do vigor da planta. A senescência ocorre de forma mais pronunciada no final do ciclo, tendo início com a bulbificação, quando parte dos compostos orgânicos e inorgânicos é translocada para os bulbos (Werner, 1986). Dessa forma, a diferença observada em relação ao número de folhas pode ser devido ao aumento do ciclo vegetativo em diferentes proporções entre as cultivares, atrasando a senescência e alterando o número de folhas na época de avaliação. A alta correlação entre o número de folhas e a produtividade observada neste trabalho está de acordo com outros trabalhos (Thakur et al., 1997; Baghalian et al., 2006).

$\mathrm{O}$ aumento da massa fresca de raízes foi significativo para todas as cultivares (Tabela 1); entretanto, apenas a cultivar Roxo Pérola de Caçador apresentou aumento do comprimento do sistema radicular. Dessa forma, presume-se que o aumento da massa fresca do sistema radicular das cultivares Quitéria e Roxo Caxiense esteja relacionado ao aumento do número de raízes, fator não avaliado neste trabalho. Contudo, o aumento da massa fresca de raízes não se traduziu em incremento de massa seca das mesmas. O suprimento adequado de $\mathrm{S}$ proporciona melhor desenvolvimento do sistema radicular das culturas, podendo trazer benefícios indiretos devido à absorção de outros nutrientes (Scherer, 2001).

Uma das hipóteses relacionada aos incrementos das características avaliadas é que o $\mathrm{S}^{\circ}$, dependendo das caracte- rísticas do solo, pode aumentar a solubilidade do $\mathrm{P}$ da porção não lábil (Richart et al., 2006) e do P dos formulados da adubação química (Richart, 2004), aumentando a disponibilidade de $\mathrm{P}$ para as plantas. Essa solubilização envolve a presença de vários microrganismos, principalmente do gênero Thiobacillus, sendo influenciada por fatores como temperatura, umidade, $\mathrm{pH}$, teor de matéria orgânica e outros (Horowitz \& Meurer, 2005). Contudo, as cultivares podem apresentar diferentes respostas a esse aumento de P no solo, sendo possível mensurar essas diferenças apenas por meio da análise foliar. Enquanto na cultivar Roxo Pérola de Caçador os teores foliares de $\mathrm{P}$ aumentaram em 13,51\%, na cultivar Quitéria reduziu em 11,90\% (Tabela 1). Essa diferença entre as cultivares pode estar relacionada ao estádio fisiológico de cada uma delas no momento da avaliação, igualmente ao discutido com o número de folhas, pois, o P é rapidamente redistribuído para os bulbos no período de senescência das folhas (Resende, 1997). Outro fator a ser levado em consideração é que o aumento em comprimento de raízes pode ter favorecido o aumento da absorção de $\mathrm{P}$, provocando essas diferenças nos teores foliares. Quanto aos bulbos, os teores de $\mathrm{P}$ variaram conforme a cultivar, sendo que, no Roxo Caxiense houve aumento nos valores, no Quitéria não houve alteração e no Roxo Pérola de Caçador houve redução dos teores de $\mathrm{P}$ no bulbo conforme o aumento das doses de $\mathrm{S}^{\circ}$. Essas diferenças também podem estar relacionadas aos diferentes estádios fisiológicos das cultivares no momento da avaliação ou, até mesmo, pode ser atribuída como característica intrínseca da cultivar.

Com o incremento na produtividade de aproximadamente $2 \mathrm{t} \mathrm{ha}^{-1}$ de alho obtido na dose de $100 \mathrm{~kg} \mathrm{ha}^{-1}$ de $\mathrm{S}^{\circ}$, o retorno financeiro bruto estimado seria de R\$ 6.000,00 ha-1 se for levado em consideração o preço médio de $\mathrm{R} \$$ $3,00 \mathrm{~kg}^{-1}$ obtido nos últimos dez anos (classes 5, 6 e 7) (Watanabe, 2009). No entanto, deduzindo o valor de $\mathrm{R} \$ 100,00$ $\mathrm{ha}^{-1}$ pelos $100 \mathrm{~kg}$ de $\mathrm{S}^{\circ}$ e o custo de aproximadamente $\mathrm{R} \$ 900,00 \mathrm{ha}^{-1}$ pelas três aplicações em cobertura, similar ao manejo adotado neste experimento, o 
retorno econômico líquido seria de $\mathrm{R} \$$ $5.000,00 \mathrm{ha}^{-1}$. Desta forma, a utilização do $\mathrm{S}^{\circ}$ como insumo na produção de alho pode aumentar a rentabilidade dos produtores brasileiros de alho, em vista das dificuldades enfrentadas pelo setor, devido, principalmente, aos preços do alho importado da China e Argentina, que apresentam maior competitividade que o alho brasileiro.

A adubação complementar com $\mathrm{S}^{\circ}$ induziu aumento da produtividade das três cultivares de alho estudadas. $\mathrm{O}$ aumento da produtividade esteve fortemente relacionado ao aumento do vigor da planta, como altura, número de folhas e massa fresca e seca de folhas, pseudocaule e raízes.

\section{REFERÊNCIAS}

AHMAD G; JAN A; ARIF M; JAN MT; KHATTAK RA. 2007. Influence of nitrogen and sulfur fertilization on quality of canola (Brassica napus L.) under rainfed conditions. Journal of Zhejiang University Science B 8: 731-737.

ALVAREZ VVH; DIAS LE. 1996. Enxofre: fertilidade e manejo do solo. Brasília: ABEAS/ UFV. p. 100 .

BAGHALIAN K; NAGHAVI MR; ZIAI SA; BADI HN. 2006. Post-planting evaluation of morphological characters and allicin content in Iranian garlic (Allium sativum L.) ecotypes. Scientia Horticulturae 107:405-410.

CABALLERO R; ALZUETA C; ORTIZ LT; RODRÍGUEZ ML; BARROB C; REBOLÉB A. 2001. Carbohydrate and protein fractions of fresh and dried Common Vetch at three maturity stages. Agronomy Journal 93: 1006-1013.

CRUSCIOL CAC; SORATTO RP; SILVA LM;
LEMOS LB. 2006. Aplicação de enxofre em cobertura no feijoeiro em sistema de plantio direto. Bragantia 65: 459-465.

EMBRAPA. 2006. Sistema brasileiro de classificação de solos. Rio de Janeiro: Embrapa Solos. 306 p.

FIGLIUOLO G; CANDIDO V; LOGOZZO G; MICCOLIS V; ZEULI PLS. 2001. Genetic evaluation of cultivated garlic germplasm (Allium sativum $\mathrm{L}$. and A. ampeloprasum L.). Euphytica 121:325-334.

FURTINI NETO AE; FERNANDES LA; FAQUIN V; SILVA IR; ACCIOLY AMA. 2000. Resposta de cultivares de feijoeiro ao enxofre. Pesquisa Agropecuária Brasileira 35: 567-573.

HANEKLAUS S; HOPPE L; BAHADIR M; SCHNUG E. 1997. Sulphur nutrition and alliin concentrations in Allium species. In: CRAM WJ; DE KOK LJ; STULEN I; BRUNOLD C; RENNENBERG H (eds). Sulphur metabolism in higher plants: molecular, ecophysiological and nutritional aspects. Leiden, Backhuys Publishers. 367p.

HOROWITZ N; MEURER EJ. 2005. Uso do enxofre elementar como fertilizante. Piracicaba, POTAFÓS. p.4-7.

KÖPPEN W. 1931. Grundriss der Klimakunde. Berlin: Walter de Gruyter \& Co. 388p.

LANCASTER JE; RANDLE WM. 2002. Sulphur compounds in alliums in relation to flavour quality. In: RABINOWITCH H \& CURRAH L (eds). Allium crop science: recent advances. Wallingford, CAB International. p.329-356.

MARSCHNER H. 1995. Mineral nutrition of higher plants. Orlando: Academic. 889p.

OLIVEIRA CM; SOUZA RJ; YURI JE; MOTA JH; RESENDE GM. 2004. Época de colheita e potencial de armazenamento em cultivares de alho. Horticultura Brasileira 22: 804-807.

RAIJ BV; CANTARELLA H; QUAGGIO JA; FURLANI AMC. Boletim técnico 100: Recomendações de adubação e calagem para o estado de São Paulo. 2. ed., Campinas: IAC, 1996. 285 p.

RESENDE FV. 1997. Crescimento, absorção de nutrientes, resposta à adubação nitrogenada e qualidade de bulbos de alho proveniente de cultura de tecidos. Lavras: UFLA, 139p. (Tese doutorado).

RICHART A. 2004. Disponibilidade de fósforo e enxofre para a cultura da soja e produção de biomassa da aveia na presença de fosfato natural reativo, superfosfato triplo e enxofre elementar. Cascavel: UNIOESTE, $117 \mathrm{p}$. (Dissertação mestrado).

RICHART A; LANA MC; SCHULZ LR; BERTONI JC; BRACCINI AL. 2006. Disponibilidade de fósforo e enxofre para a cultura da soja na presença de fosfato natural reativo, superfosfato triplo e enxofre elementar. Revista Brasileira de Ciências do Solo 30: 695-705.

SCHERER HW. 2001. Sulphur in crop production. European Journal of Agronomy 14: 81-111.

SMATANOVÁ M; RICHTER R; HLUSEK J. 2004. Spinach and Red Pepper Response to Nitrogen and Sul-phur Fertilization. Plant, Soil and Environment 50: 303-308.

SOUZA RJ; MACÊDO FS.2009. Cultura do Alho - Tecnologias Modernas de Produção. Lavras, editora UFLA, 181p.

SOUZA RJ; CASALI VWD. 1986. Pseudoperfilhamento: uma anormalidade genético-fisiológica em alho. Informe Agropecuário 12: 36-40.

STAHLSCHMIDT O; CAVAGNARO JB; BORGO R. 1997. Growth analysis of three garlic cultivars with differences in yield. Acta Horticulturae 433: 427-434.

THAKUR JC; BAIHAL GS; GILL SPS. 1997. Genetic variation and correlation studies in garlic. Journal of Research Punjab Agricultural University 34: 40-44.

THOMAZ EL; VESTENA LR. 2003. Aspectos climáticos de Guarapuava-PR. Guarapuava: UNICENTRO, 106p.

WATANABE T. 2009. Alho: situação da comercialização. Disponível em: www.anapa. com.br/principal/images/stories/documentos/ alho_fevereiro_2009.pdf. Acesso em 01 de julho 2009.

WERNER RA. 1986. Manejo pós colheita do alho. Informe agropecuário 12: 46-49. 